\title{
Gambaran upaya penurunan berat badan melalui olahraga aerobik pada remaja obes Kelas X Tahun 2016 di SMA Kristen Irene Manado
}

\author{
${ }^{1}$ Erick Tungka \\ ${ }^{2}$ Hendri Opod \\ ${ }^{2}$ Lidya David
}

\author{
${ }^{1}$ Kandidat Skripsi Fakultas Kedokteran Universitas Sam Ratulangi Manado \\ ${ }^{2}$ Bagian Psikologi Fakultas Kedokteran Universitas Sam Ratulangi Manado \\ Email: etungka_11_247@yahoo.com
}

\begin{abstract}
Nationally, the incidence of obesity in ages 13-15 years is $4.5 \%$ in males and $2.9 \%$ in females. In North Sulawesi, the incidence of obesity in ages 13-15 years is 3\% in males and 3.8\% in females. This was a descriptive study. Data were obtained by filling questionnaires and direct observation together with the sport teachers at the sport field of KONI Sario Manado. Aerobic exercices (jogging and running) 1 hour per week were performed for four weeks. Respondents were 8 obese male respondents and 8 female obese respondents Of the 16 respondents, 9 had less knowledge about high-fat foods, cholesterol, and calories; 7 had good knowledge about that. In terms of attitudes and actions, 16 respondents did not follow a balanced and healthy diet. After the 4-week aerobic exercise, the mean weight loss of male respondents was $0.15 \mathrm{~kg}$ and of female respondents was $0.20 \mathrm{~kg}$. Among male respondents, the mean fat loss was $0.2 \mathrm{~cm}$ in arm circumference, $0.25 \mathrm{~cm}$ in abdominal circumference, and $0.15 \mathrm{~cm}$ in thigh circumference meanwhile among the female respondents, the mean fat loss was $0.21 \mathrm{~cm}$ in arm circumference, $0.18 \mathrm{~cm}$ in abdominal circumference, and $0.30 \mathrm{~cm}$ in thigh circumference. Conclusion: All respondents did not follow a balanced and healthy diet. The numbers of respondents with poor knowledge and of respondents with good knowledge about high-fat foods, cholesterol, and calories were nearly the same. After aerobic exercise, there were decreases in body weight, arm circumference, abdominal circumference, and thigh circumference among male and female respondents.
\end{abstract}

Keywords: diet management, balanced menu, aerobic exercise

\begin{abstract}
Abstrak: Kejadian obesitas secara nasional di usia 13-15 tahun pada laki-laki ialah 4,5\% dan pada perempuan 2,9\%. Di Sulawesi Utara kejadian obesitas di usia 13-15 tahun pada laki-laki 3\% dan pada perempuan $3,8 \%$. Penelitian ini bertujuan untuk mendapatkan gambaran upaya penurunan berat badan melalui olahraga aerobik pada remaja obes Kelas X Tahun 2016 di SMA Kristen Irene Manado. Jenis penelitian ialah deskriptif. Pengambilan data pengisian kuesioner dari 8 responden laki-laki obes dan 8 responden perempuan obes dan melalui observasi langsung peneliti bersama guru olahraga di lapangan KONI Sario Manado. Latihan aerobik (jogging dan lari cepat, bergantian) selama 1 jam per minggu dilakukan selama 4 minggu. Dalam hal pengetahuan tentang makanan berlemak, kolesterol, dan kalori, dari total 16 responden diperoleh 9 orang berpengetahuan kurang dan 7 orang berpengetahuan baik. Dalam hal sikap dan tindakan, seluruh responden tidak mengikuti pola makan menu seimbang dan sehat. Rerata penurunan berat badan sesudah olahraga aerobik pada responden laki-laki $0,15 \mathrm{~kg}$ dan pada responden perempuan 0,20 $\mathrm{kg}$. Rerata penurunan lemak sesudah olahraga aerobik pada responden laki-laki lingkar lengan 0,2 $\mathrm{cm}$, lingkar perut $0,25 \mathrm{~cm}$, lingkar paha $0,15 \mathrm{~cm}$ sedangkan pada responden perempuan lingkar lengan $0,21 \mathrm{~cm}$, lingkar perut $0,18 \mathrm{~cm}$, lingkar paha $0,30 \mathrm{~cm}$. Simpulan: Seluruh responden tidak mengikuti pola makan menu seimbang. Jumlah responden dengan pengetahuan kurang dan pengetahuan baik mengenai makanan berlemak, kolesterol, dan kalori hampir sama banyak. Setelah latihan olahraga aerobik didapatkan penurunan rerata dari berat badan, lingkar lengan, lingkar perut, dan lingkar paha baik pada responden laki-laki maupun perempuan.
\end{abstract}

Kata kunci: pola makan, menu seimbang, olahraga aerobik 

Di Indonesia prevelensi obesitas penduduk usia >15 tahun pada laki-laki sebesar $10,3 \%$ dan pada perempuan $13,9 \%$. Berdasarkan data tersebut disimpulkan bahwa obesitas di Indonesia telah menjadi masalah nasional yang harus segera ditangani. Di Sulawesi Utara kejadian obesitas usia 13-15 tahun ialah pada lakilaki $3 \%$ dan perempuan $3,8 \%$. $^{1}$ Kejadian obesitas diakibatkan oleh pola hidup tidak aktif dengan adanya kemajuan teknologi seperti transportasi bermotor, lift, pendingin ruangan, pemanas ruangan, dan internet sehingga energi bergerak lebih sedikit, aktifitas fisik hanya menonton televisi, bermain video game. Adanya makanan cepat saji yang diminati pelajar SMA terutama di kota-kota yang mengandung banyak kalori, lemak dan kolesterol mengakibatkan gizi lebih dan obesitas. Hal ini terjadi karena kurangnya pengetahuan mengenai pola makan dengan prinsip menu seimbang alami dan sehat. ${ }^{1-4}$

Obesitas adalah keadaan yang menunjukkan ketidakseimbangan antara tinggi dan berat badan akibat akumulasi jaringan lemak dalam tubuh sehingga terjadi kelebihan berat badan yang melampaui ukuran ideal. ${ }^{5}$ Kejadian obesitas akan meningkatkan risiko penyakit jantung dan kardiovaskular. ${ }^{6-9}$ Derajat obesitas menurut Misnadiarly ialah sebagai berikut: ${ }^{10}$

1. Obesitas ringan: 20-40\% kelebihan lemak dari berat badan ideal

2. Obesitas sedang: 41-100\% kelebihan lemak dari berat badan ideal

3. Obesitas berat: lebih dari $101 \%$ kelebihan lemak dari berat badan ideal

yang dihitung dengan rumus sebagai berikut:

$$
\text { IMT } \frac{\text { Berat Badan (Kilogram) }}{\text { Badan }^{2}\left(\text { Meter }^{2}\right)}
$$

Olahraga aerobik yang dilakukan ialah: antara lain jalan cepat, lari-lari kecil (jogging), lari cepat, dan senam intensitas ringan.

Penelitian ini bertujuan untuk mengetahui perilaku remaja (siswa) obes ringan terhadap pengenalan olahraga aerobik; mengetahui sikap, pengetahuan dan tindakan tentang pola hidup sehat, menu seimbang dan alami; dan mengetahui penurunan berat badan dan penurunan lemak remaja obes (siswa) laki-laki dan perempuan.

\section{METODE PENELITIAN}

Jenis penelitian ini ialah deskriptif dengan mengumpulkan data yang ada di lapangan secara aktual dan memberi gambaran tentang apa yang terjadi di lapangan secara nyata dan dapat dilihat dengan mata (fenomena). Penelitian dilaksanakan di SMA Kristen Irene Manado selama bulan Juli sampai bulan September 2016. Olahraga aerobik berupa jogging dan lari cepat (bergantian) durasi 1 jam per minggu selama 4 minggu berturut yang dilaksanakan di lapangan KONI Sario Manado.

Sampel penelitian diambil dengan cara penelitian populasi. Populasi seluruh siswa kelas X SMA Kristen Irene Manado Tahun 2016 sebanyak 63 orang. Siswa yang obes ringan terdiri dari 8 orang siswa laki-laki dan 8 orang siswa perempuan.

Data diperoleh melalui pengukuran langsung tinggi badan (TB), berat badan (BB), lingkar lengan (LL), lingkar perut (LP), dan lingkar paha dalam sentimeter pada responden. Data yang diperoleh diproses dengan menggunakan tabel distribusi frekuensi.

\section{HASIL PENELITIAN}

Penelitian dilakukan pada bulan Juli sampai bulan September 2016 di SMA Kristen Irene Manado Kelas X dengan jumlah siswa 63 orang. Hasil penelitian disajikan dalam bentuk tabel distribusi frekuensi.

Distribusi frekuensi karakteristik responden dapat dilihat pada Tabel 1 sedangkan distribusi frekuensi berdasarkan pengetahuan, sikap, dan tindakan responden dapat dilihat pada Tabel 2, 3, dan 4.

Distribusi frekuensi rerata tinggi badan (TB), rerata berat badan (BB) sebelum olahraga aerobik, rerata berat badan 
sesudah olahraga aerobik dan rerata penurunan berat badan sesudah olahraga aerobik pada responden laki-laki dan perempuan dapat dilihat pada Tabel 5 dan Tabel 6.
Distribusi frekuensi karakteristik responden berdasarkan penurunan lemak lingkar lengan, penurunan lemak lingkar perut, dan penurunan lemak lingkar paha dapat dilihat pada Tabel 7-12.

Tabel 1. Distribusi frekuensi karakteristik responden berdasarkan berat badan sesuai Indeks Massa Tubuh (IMT)

\begin{tabular}{|c|c|c|c|c|}
\hline \multirow{2}{*}{$\begin{array}{l}\text { Berat badan } \\
\text { sesuai IMT }\end{array}$} & \multicolumn{2}{|c|}{ Frekuensi } & \multicolumn{2}{|c|}{ Persentase (\%) } \\
\hline & Laki-laki & Perempuan & Laki-laki & Perempuan \\
\hline Kurang gizi & 1 & 1 & 1,58 & 1,58 \\
\hline Berat badan ideal & 20 & 25 & 31,74 & 39,68 \\
\hline Obesitas ringan & 8 & 8 & 12,69 & 12,69 \\
\hline Obesitas sedang & - & - & - & - \\
\hline Obesitas berat & - & - & - & - \\
\hline Jumlah & 29 & 34 & 46,01 & 53.95 \\
\hline Total & \multicolumn{2}{|c|}{63} & \multicolumn{2}{|c|}{100} \\
\hline
\end{tabular}

Tabel 2. Distribusi frekuensi berdasarkan pengetahuan responden mengenai pola makan dan olahraga

\begin{tabular}{ccccc}
\hline \multirow{2}{*}{ Kategori } & \multicolumn{2}{c}{ Frekuensi } & \multicolumn{2}{c}{ Persentase (\%) } \\
& Laki-laki & Perempuan & Laki-laki & Perempuan \\
\hline Baik & 3 & 4 & 18,73 & 25 \\
Kurang & 5 & 4 & 31,25 & 25 \\
Jumlah & 8 & 8 & 50 & 50 \\
\hline
\end{tabular}

Tabel 3. Distribusi frekuensi berdasarkan sikap responden mengenai pola makan dan olahraga

\begin{tabular}{ccccc}
\hline \multirow{2}{*}{ Kategori } & \multicolumn{2}{c}{ Frekuensi } & \multicolumn{2}{c}{ Persentase (\%) } \\
& Laki-Laki & Perempuan & Laki-Laki & Perempuan \\
\hline Baik & 3 & 4 & 31,25 & 12,5 \\
Kurang & 5 & 4 & 18,73 & 37,5 \\
Jumlah & 8 & 8 & 50 & 50 \\
\hline
\end{tabular}

Tabel 4. Distribusi frekuensi berdasarkan tindakan responden mengenai pola makan dan oahraga

\begin{tabular}{ccccc}
\hline \multirow{2}{*}{ Kategori } & \multicolumn{2}{c}{ Frekuensi } & \multicolumn{2}{c}{ Persentase (\%) } \\
& Laki-laki & Perempuan & Laki-laki & Perempuan \\
\hline Baik & - & - & - & - \\
Kurang & 8 & 8 & 50 & 50 \\
Jumlah & 8 & 8 & 50 & 50 \\
\hline
\end{tabular}

Tabel 5. Distribusi frekuensi karakteristik rerata tinggi badan (TB), rerata berat badan (BB) sebelum dan sesudah olahraga aerobik, serta rerata penurunan berat badan sesudah olahraga aerobik pada responden laki-laki

\begin{tabular}{|c|c|c|c|c|c|}
\hline \multicolumn{6}{|c|}{ Responden laki-laki } \\
\hline Rerata TB & $\begin{array}{c}\text { Rerata BB } \\
\text { sebelum } \\
\text { olahraga } \\
\text { aerobik }\end{array}$ & $\begin{array}{c}\text { Rerata BB } \\
\text { sesudah } \\
\text { olahraga } \\
\text { aerobik }\end{array}$ & $\begin{array}{c}\text { Rerata penurunan } \\
\text { BB sesudah } \\
\text { olahraga aerobik }\end{array}$ & Frekuensi & $\begin{array}{c}\text { Persentase } \\
(\%)\end{array}$ \\
\hline $1,55 \mathrm{~cm}$ & $63,87 \mathrm{~kg}$ & $63,71 \mathrm{~kg}$ & $0,16 \mathrm{~kg}$ & 8 & 50 \\
\hline
\end{tabular}


Tungka, Opod, David: Gambaran upaya penurunan berat badan ...

Tabel 6. Distribusi frekuensi karakteristik rerata tinggi badan (TB), rerata berat badan (BB) sebelum dan sesudah olahraga aerobik, serta rerata penurunan berat badan sesudah olahraga aerobik pada responden perempuan

\begin{tabular}{cccccc}
\hline \multicolumn{7}{c}{ Responden perempuan } & & \\
Rerata TB & $\begin{array}{c}\text { Rerata BB } \\
\text { sebelum } \\
\text { olahraga } \\
\text { aerobik }\end{array}$ & $\begin{array}{c}\text { Rerata BB } \\
\text { sesudah } \\
\text { olahraga } \\
\text { aerobik }\end{array}$ & $\begin{array}{c}\text { Rerata penurunan } \\
\text { BB sesudah } \\
\text { olahraga aerobik }\end{array}$ & Frekuensi & $\begin{array}{c}\text { Persentase } \\
(\%)\end{array}$ \\
\hline $1,60 \mathrm{~cm}$ & $66,87 \mathrm{~kg}$ & $66,67 \mathrm{~kg}$ & $0,20 \mathrm{~kg}$ & 8 & 50 \\
\hline
\end{tabular}

Tabel 7. Distribusi frekuensi karakteristik berdasarkan penurunan lemak lingkar lengan (LL) pada responden laki-laki

\begin{tabular}{cccccc}
\hline & \multicolumn{3}{c}{ Responden laki-laki } & & \\
Rerata TB & $\begin{array}{c}\text { Lerata lemak } \\
\text { olahraga } \\
\text { aerobik }\end{array}$ & $\begin{array}{c}\text { Rerata lemak } \\
\text { LL sesudah } \\
\text { olahraga } \\
\text { aerobik }\end{array}$ & $\begin{array}{c}\text { Rerata penurunan } \\
\text { lemak LL sesudah } \\
\text { olahraga aerobik }\end{array}$ & Frekuensi & $\begin{array}{c}\text { Persentase } \\
(\boldsymbol{\%})\end{array}$ \\
\hline $1,55 \mathrm{~cm}$ & $21,62 \mathrm{~cm}$ & $21,38 \mathrm{~cm}$ & $0,24 \mathrm{~cm}$ & $8 \mathrm{org}$ & 50 \\
\hline
\end{tabular}

Tabel 8. Distribusi frekuensi karakteristik berdasarkan penurunan lemak lingkar lengan (LL) pada responden perempuan

\begin{tabular}{cccccc}
\hline \multirow{2}{*}{ Rerata TB } & $\begin{array}{c}\text { Rerata lemak } \\
\text { LL sebelum } \\
\text { olahraga } \\
\text { aerobik }\end{array}$ & $\begin{array}{c}\text { Responden perempuan } \\
\text { Rerata lemak } \\
\text { olahraga } \\
\text { aerobik }\end{array}$ & $\begin{array}{c}\text { Rerata penurunan } \\
\text { lemak LL sesudah } \\
\text { olahraga aerobik }\end{array}$ & Frekuensi & $\begin{array}{c}\text { Persentase } \\
(\boldsymbol{\%})\end{array}$ \\
\hline $1,60 \mathrm{~cm}$ & $24,93 \mathrm{~cm}$ & $24,74 \mathrm{~cm}$ & $0,19 \mathrm{~cm}$ & 8 & 50 \\
\hline
\end{tabular}

Tabel 9. Distribusi frekuensi karakteristik berdasarkan penurunan lemak lingkar perut (LP) pada responden laki-laki

\begin{tabular}{cccccc}
\hline \multirow{2}{*}{ Rerata TB } & $\begin{array}{c}\text { Rerata lemak } \\
\text { LP sebelum } \\
\text { olahraga } \\
\text { aerobik }\end{array}$ & $\begin{array}{c}\text { Rerata lemak } \\
\text { LP sesudah } \\
\text { olahraga } \\
\text { aerobik }\end{array}$ & $\begin{array}{c}\text { Rerata penurunan } \\
\text { lemak LP sesudah } \\
\text { olahraga aerobik }\end{array}$ & Frekuensi & $\begin{array}{c}\text { Persentase } \\
(\%)\end{array}$ \\
\hline $1,55 \mathrm{~cm}$ & $80,37 \mathrm{~cm}$ & $80,11 \mathrm{~cm}$ & $0,26 \mathrm{~cm}$ & 8 & 50 \\
\hline
\end{tabular}

Tabel 10. Distribusi frekuensi karakteristik berdasarkan penurunan lemak lingkar perut (LP) pada responden perempuan

\begin{tabular}{cccccc}
\hline \multirow{2}{*}{ Rerata TB } & $\begin{array}{c}\text { Rerata lemak } \\
\text { LP sebelum } \\
\text { olahraga } \\
\text { aerobik }\end{array}$ & $\begin{array}{c}\text { Responden perempuan } \\
\text { Rerata lemak } \\
\text { LP sesudah } \\
\text { olahraga } \\
\text { aerobik }\end{array}$ & $\begin{array}{c}\text { Rerata penurunan } \\
\text { lemak LP sesudah } \\
\text { olahraga aerobik }\end{array}$ & Frekuensi & $\begin{array}{c}\text { Persentase } \\
(\boldsymbol{\%})\end{array}$ \\
\hline $1,60 \mathrm{~cm}$ & $73,25 \mathrm{~cm}$ & $73,06 \mathrm{~cm}$ & $0,19 \mathrm{~cm}$ & 8 & 50 \\
\hline
\end{tabular}


Tabel 11. Distribusi frekuensi karakteristik berdasarkan penurunan lemak lingkar paha pada responden laki-laki

\begin{tabular}{|c|c|c|c|c|c|}
\hline \multicolumn{6}{|c|}{$\underline{\text { Responden laki-laki }}$} \\
\hline Rerata TB & $\begin{array}{c}\text { Rerata lemak } \\
\text { lingkar paha } \\
\text { sebelum } \\
\text { olahraga } \\
\text { aerobik }\end{array}$ & $\begin{array}{c}\text { Rerata lemak } \\
\text { lingkar paha } \\
\text { sesudah } \\
\text { olahraga } \\
\text { aerobik }\end{array}$ & $\begin{array}{c}\text { Rerata penurunan } \\
\text { lemak lingkar paha } \\
\text { sesudah olahraga } \\
\text { aerobik }\end{array}$ & Frekuensi & $\begin{array}{c}\text { Persentase } \\
(\%)\end{array}$ \\
\hline $1,55 \mathrm{~cm}$ & $47,62 \mathrm{~cm}$ & $47,47 \mathrm{~cm}$ & $0,15 \mathrm{~cm}$ & 8 & 50 \\
\hline
\end{tabular}

Tabel 12. Distribusi frekuensi karakteristik berdasarkan penurunan lemak lingkar paha pada responden perempuan

\begin{tabular}{cccccc}
\hline \multirow{2}{*}{ Rerata TB } & $\begin{array}{c}\text { Rerata lemak } \\
\text { lingkar paha } \\
\text { sebelum } \\
\text { olahraga } \\
\text { aerobik }\end{array}$ & $\begin{array}{c}\text { Responden perempuan } \\
\text { Rerata lemak } \\
\text { lingkar paha } \\
\text { sesudah } \\
\text { olahraga } \\
\text { aerobik }\end{array}$ & $\begin{array}{c}\text { Rerata penurunan } \\
\text { lemak lingkar paha } \\
\text { sesudah olahraga } \\
\text { aerobik }\end{array}$ & Frekuensi & $\begin{array}{c}\text { Persentase } \\
(\%)\end{array}$ \\
\hline $1,60 \mathrm{~cm}$ & $34,73 \mathrm{~cm}$ & $34,63 \mathrm{~cm}$ & $0,10 \mathrm{~cm}$ & 8 & 50 \\
\hline
\end{tabular}

\section{BAHASAN}

Penelitian ini dilakukan terhadap siswa SMA Kristen Irene Manado Kelas X tahun 2016 dengan jumlah siswa sebanyak 63 orang. Tabel 1 memperlihatkan bahwa berdasarkan berat badan sesuai IMT dari 63 orang siswa didapatkan 10 siswa laki-laki dan 1 siswa perempuan yang kurang gizi; tinggi badan dan berat badan ideal sebanyaki 20 siswa laki-laki dan 25 siswa perempuan; dan obesitas ringan pada 8 siswa laki-laki dan 8 siswa perempuan. Tidak ditemukan siswa dengan obesitas sedang dan berat. Hal ini mungkin diakibatkan karena masih kurangnya pengetahuan tentang makanan bergizi karena hal tersebut tidak diajarkan secara khusus di SD dan SMP sehingga orang tua dan siswa kurang menghayati tentang makanan bergizi menu seimbang dan sehat.

Tabel 2 memperlihatkan 8 responden laki-laki dan 8 responden perempuan menjawab bahwa mereka makan pagi, siang, dan malam namun orang tua mereka tidak mengajarkan pola makan seimbang dan sehat. Setiap minggu makan di restoran cepat saji rata-rata 2 sampai 3 kali. Terdapat 9 responden menjawab yang penting makan enak dan 7 responden mengerti makanan di restoran cepat saji khususnya daging banyak mengandung kalori, lemak, dan kolesterol.

Pada Tabel 3 terdapat 8 responden laki-laki dan 8 responden perempuan setuju bahwa obesitas bukan merupakan penyakit. Sikap lain dari responden ialah 7 responden berpendapat obesitas penyebab timbulnya penyakit. Terdapat 9 responden yang mempunyai sikap mengikuti petunjuk orang tua yaitu banyak makan daging agar sehat dan makanan yang sudah diambil di piring nasi, ikan, sayur, daging harus dihabiskan meskipun sudah kenyang. Selain itu, 16 responden mempunyai sikap tidak melaksanakan kerja fisik dan olahraga karena kurang pengetahuan tentang olahraga yang membuat badan sehat.

Pada Tabel 4 terdapat 8 responden laki-laki dan 8 responden perempuan bertindak makan sampai kenyang sepuasnya tidak mengikuti pola makan menu seimbang dan sehat, makan di restoran cepat saji rata-rata 2 sampai 3 kali seminggu, dan tidak ada kesadaran untuk olahraga. Hal ini merupakan tindakan yang dikategorikan kurang untuk menjaga tinggi dan berat badan ideal.

Pada responden laki-laki, rerata tinggi badan $1,55 \mathrm{~cm}$ dan rerata berat badan $64 \mathrm{~kg}$. Rerata penurunan berat badan responden 
laki-laki sebelum dan sesudah olahraga aerobik sebesar $0,15 \mathrm{~kg}$ (Tabel 5). Pada responden perempuan, rerata tinggi badan $1,60 \mathrm{~cm}$ dan rerata berat badan $67 \mathrm{~kg}$. Rerata penurunan berat badan sesudah olahraga aerobik didapatkan sebesar 0,20 $\mathrm{kg}$ (Tabel 6). Rerata penurunan berat badan didapatkan lebih besar pada responden perempuan dibandingkan responden lakilaki. Hal ini mugkin disebabkan karena responden perempuan lebih serius menyikapi efek penurunan berat badan dari olahraga aerobik dibandingkan responden laki-laki. Dengan mempelajari makanan bergizi dan mengikuti pola makan menu seimbang dan sehat serta melaksanakan olahraga aerobik rata-rata setiap minggu 90 menit maka akan tercapai berat badan ideal. ${ }^{11}$

Pada responden laki-laki, rerata lemak lingkar lengan (LL) sebelum olahraga aerobik $21,50 \mathrm{~cm}$ dan sesudah olahraga aerobik $21,25 \mathrm{~cm}$ dengan penurunan rerata lemak LL 0,25 cm (Tabel 7). Pada responden perempuan rerata lemak lingkar lengan sebelum olahraga aerobik $25,50 \mathrm{~cm}$ dan sesudah olahraga aerobik $25,30 \mathrm{~cm}$ dengan penurunan rerata lemak LL $0,20 \mathrm{~cm}$ (Tabel 8).

Rerata lemak lingkar perut (LP) responden laki-laki sebelum olahraga aerobik $81,50 \mathrm{~cm}$ dan sesudah olahraga aerobik $81,25 \mathrm{~cm}$ dengan penurunan rerata lemak LP $0,25 \mathrm{~cm}$ (Tabel 9). Pada responden perempuan rerata lemak LP sebelum olahraga aerobik $73,50 \mathrm{~cm}$ dan sesudah olahraga aerobik dengan penurunan rerata lemak LP 0,20 cm (Tabel 10).

Rerata lemak lingkar paha responden laki-laki sebelum olahraga aerobik $48 \mathrm{~cm}$ dan sesudah olahraga aerobik 47,85 cm dengan penurunan rerata lemak lingkar paha $0,15 \mathrm{~cm}$ (Tabel 11) sedangkan pada responden perempuan rerata lemak lingkar paha sebelum olahraga aerobik $35 \mathrm{~cm}$ dan sesudah olahraga aerobik $34,90 \mathrm{~cm}$ dengan penurunan rerata lemak lingkar paha 0,10 cm (Tabel 12).

\section{SIMPULAN}

Seluruh responden tidak mengikuti pola makan menu seimbang. Jumlah responden dengan pengetahuan kurang dan pengetahuan baik mengenai makanan berlemak, kolesterol, dan kalori hampir sama banyak. Setelah latihan olahraga aerobik didapatkan penurunan rerata dari berat badan, lingkar lengan, lingkar perut, dan lingkar paha baik pada responden lakilaki maupun perempuan.

\section{DAFTAR PUSTAKA}

1. Departemen Kesehatan Republik Indonesia, Obesitas dan kurang aktivitas fisik. Jakarta, 2011.

2. Suparyanto. Gizi seimbang untuk remaja, ibu hamil, dewasa, dan usia lanjut. Available from: drsuparyanto.blogspot.com/.../konsepdasar-menu-seimbang.html. 2005.

3. World Health Organization (WHO) Fact sheet: Obesity and overweight Available from: www.who.int/ mediacentre/factsheets/fs311/en/

4. Wiramihardja KK. Obesitas dan Penanggulangannya. Bandung:: Granada, 2000.

5. Dohle S, Rall S, Siegrist M. Does selfprepared food taste better? Effects of food preparation on liking. Health Psychol. 2016;35(5):500-8.

6. Kusmana D. Olahraga bagi Kesehatan Jantung. Jakarta: Fakultas Kedokteran UI, 2002.

7. Sadoso S. Pengetahuan Praktis Kesehatan dan Olahraga. Jakarta: Gramedia Pustaka Utama, 1990.

8. Soeharto I. Pencegahan dan Penyembuhan Penyakit Jantung Koroner. Jakarta: Gramedia Pustaka Utama, 2001.

9. Visscher TLS, Seidell JC. The Public Health Impact of Obesity. Annu Rev Public health. 2001;22:355-75.

10. Agustrisno. Derajat obesitas, (homepage in the internet). No date, 2011.

11. Goldstein RL, Cotton RT. Aerobic Instructor Manual: The Resource for Fitness. Amer Counsil on Exercise, 1993. 